\title{
Hematological and serum biochemical analyses in experimental caprine coccidiosis
}

\author{
Mohammad Hashemnia • Azizollah Khodakaram-Tafti • \\ Seyed Mostafa Razavi $\cdot$ Saeed Nazifi
}

Received: 9 March 2012/Accepted: 2 November 2012/Published online: 17 November 2012

(C) Indian Society for Parasitology 2012

\begin{abstract}
In order to provide information on hematological and biochemical changes in Eimeria arloingi infection, eighteen newborn kids were allocated to three equal groups. Two groups, A and B were inoculated with a single dose of $1 \times 10^{3}$ and $1 \times 10^{5}$ sporulated oocysts of E. arloingi, respectively. The third group $\mathrm{C}$ remained uninfected as control. Blood samples were collected from jugular vein before inoculation as control and at 7, 14, 21, 28,35 and 42 days post inoculation (DPI). Total erythrocyte and total leukocyte counts, hemoglobin (Hb), packed cell volume (PCV) and differential leukocyte counts were determined. Serum biochemical parameters including total protein (TP), albumin, chloride $\left(\mathrm{Cl}^{-}\right)$, sodium $\left(\mathrm{Na}^{+}\right)$, potassium $\left(\mathrm{K}^{+}\right)$, aspartate aminotransferase (AST), alanine aminotransferase (ALT), alkaline phosphatase (ALP), and gamma glutamyltransferase (GGT) were measured. All infected animals showed symptoms of clinical coccidiosis including diarrhea and oocyst excretion after the prepatent period that varied from 16 to 18 days after inoculation. The oocysts output did not stop until the end of the experiment. The diarrhea was associated with a reduction in ALP activity, increases in PCV and $\mathrm{Hb}$ and decreases in $\mathrm{Na}^{+}$, $\mathrm{Cl}^{-}$and $\mathrm{K}^{+}$. No significant differences were found in AST, ALT, GGT, albumin and TP during 42 DPI. There was no hepatic damage.
\end{abstract}

M. Hashemnia ( $₫)$ · A. Khodakaram-Tafti · S. M. Razavi Department of Pathobiology, School of Veterinary Medicine, Shiraz University, P.O. Box 71345-1731, Shiraz, Iran e-mail: hashemnia@shirazu.ac.ir

S. Nazifi

Department of Clinical Studies, School of Veterinary Medicine, Shiraz University, P.O. Box 71345-1731, Shiraz, Iran
Keywords Eimeria arloingi - Coccidiosis ·

Serum biochemical parameters $\cdot$ Hematology $\cdot$ Kids

\section{Introduction}

Coccidiosis is a disease of both domestic and wild animals with a worldwide distribution (Soulsby 1982; KhodakaramTafti and Mansourian 2008). Parasites of the genus Eimeria are classified in the subfamily Eimeriinae of the phylum Apicomplexa (Bush et al. 2001). Species of the coccidian genus Eimeria parasitize cattle, poultry, sheep, goats, pigs, horses, rabbits and rodents (Cox 1998). Several Eimeria species have been shown to be capable of establishing clinical disease in goats associated with diarrhea, low growth performance, decrease in productivity, high morbidity, and, depending on which Eimeria species is dominant, high mortality rates as well (Radostits et al. 1994). The mortality rate can even be as high as $58 \%$ (Jalila et al. 1998). Stress factors such as weaning, inclement weather, dietary changes, traveling and regrouping have important roles in caprine coccidiosis (Cox 1998).

The studies in many countries such as the Netherlands (Borgsteede and Dercksen 1996), Czech Republic (Koudela and Bokova 1998), Malaysia (Jalila et al. 1998), Poland (Balicka-Ramisz 1999), South Africa (Harper and Penzhorn 1999), Sri Lanka (Faizal and Rajapakse 2001), Iraq (Al-Amery and Hasso 2002), Jordan (Abo-Shehada and Abo-Farieha 2003), Turkey (Gul 2007) and Iran (Razavi and Hassanvand 2007) have indicated that coccidiosis is an important clinical and subclinical disease which may be associated with significant economic losses in the small ruminant industry.

More than 15 Eimeria species were identified in goats from which E. arloingi, E. ninakohlyakimovae, E. christenseni and 
E. caprina are the most common pathogenic species (Koudela and Bokova 1998; Sayin et al. 1980; Jalila et al. 1998; Razavi and Hassanvand 2007).

Although we showed some evidences of the life cycle and morphopathological lesions of coccidiosis in kids experimentally infected by $E$. arloingi in previous study (Hashemnia et al. 2011), no report is available about the hematological and biochemical changes in caprine coccidiosis. Therefore, the present study was conducted to elucidate the hematological and biochemical changes in experimentally $E$. arloingi-infected kids from early infection to 42 days post-infection.

\section{Materials and methods}

Preparation of E. arloingi oocysts

A pure strain of E. arloingi was obtained from the Parasitology Department of Shiraz University. The oocysts were stored at $4{ }^{\circ} \mathrm{C}$ in $2.5 \%$ potassium dichromate $\left(\mathrm{K}_{2} \mathrm{Cr}_{2} \mathrm{O}_{7}\right)$ solution for about three weeks before their use in the experiment. Before inoculation, the suspension was freed of potassium dichromate solution by series washing and centrifuging at $750 \times g$ for $5 \mathrm{~min}$. The sediment mixed with 100-ml distilled water and the number of oocysts was calculated for each $\mathrm{ml}$ of suspension.

Experimental animals and design

Eighteen Iranian crossbred kids were separated from their dams immediately after birth, fed with a milk replacer and reared under coccidia-free conditions in closed rooms with restricted access. After two weeks, the kids were divided into three groups. The kids of groups $\mathrm{A}(n=6)$ and $\mathrm{B}(n=6)$ were infected orally with $1 \times 10^{3}$ (low dose) and $1 \times 10^{5}$ (high dose) sporulated oocysts of E. arloingi per animal, respectively as reported by Dai et al. (2006). The kids in group C $(n=6)$ remained uninfected as control.

\section{Parasitological examination}

All kids were observed for a period of 6 weeks from day 7 post-infection. Fresh faecal samples, approximately 3-5 g, were taken by anus stimulation and were examined for the presence of oocysts every day. The OPG (oocyst per gram) was determined by modified McMaster method (MAFF 1977). Faecal consistency was assessed on the basis of a scoring system (1: normal, 2: semiliquid to liquid, 3: watery, 4: hemorrhagic and/or with tissue).
Hematological and biochemical analyses

Blood samples were collected from the jugular vein in all groups before inoculation as control and at 7, 14, 21, 28, 35, and 42 DPI. The blood samples were collected in vacutainers containing EDTA for hematological factors and into vacutainers without anticoagulant for biochemical analysis. The collected sera were separated by centrifugation at $750 \times g$ for $15 \mathrm{~min}$ and stored at $-20 \mathrm{C}$ until be analyzed. Hematological analysis including total erythrocyte count, total leukocyte count, hematocrit value and hemoglobin concentration was determined using standard routine techniques. For differential leukocyte counts, the blood smears were prepared and stained with Giemsa stain (Jain 1986). Serum total protein (TP) was measured by the Biuret method, albumin by the bromcresol green method and chloride by the mercuric thiocyanate colorimetric method. Sodium and potassium contents of serum were determined using a flame photometer (Model CL 26D ELICO, UK). Serum aspartate aminotranferase (AST) and alanine aminotranferase (ALT) activities were measured by the colorimetric method of Reitman and Frankel, alkaline phosphatase (ALP) by the modified method of Bowers and McComb and gamma glutamyltransferase (GGT) by the modified method of Szasz. All the enzyme activities were measured at $37{ }^{\circ} \mathrm{C}$ and the results presented in units per liter (Burtis and Ashwood 1994). Biochemical analyses were measured using a standard autoanalyser with veterinary software (Cobas-Mira, ABX-Diagnostics, Japan).

Statistical analysis

Descriptive statistics including the mean, standard deviation, median, minimum and maximum were calculated for all variables. The ANOVA and Tukey tests were used for comparison of different parameters. Data were analyzed by SPSS software, version 16 and $P<0.05$ was accepted as statistically significant.

\section{Results}

Oocysts output

The prepatent period varied between 16 and 18 days in groups $\mathrm{A}$ and $\mathrm{B}$. The change in the faeces appearance coincided with the first appearance of oocysts in both groups. In group A, diarrhea started from 20 DPI, one kid with semi liquid and the others with liquid diarrhea (score 2). Severe diarrhea with variable amounts of mucus (score 3) occurred in group B from 18 DPI. The kids in group A began to shed the oocysts from 16 DPI. The peak shed occured 24-32 DPI and the peak number of oocysts was 
$138 \times 10^{3}\left(16 \times 10^{3}-295 \times 10^{3}\right)$ per gram of faeces. In group B, the prepatent period was 18 DPI. The peak shed occured 19-28 DPI and the peak number of oocysts was $12 \times 10^{5}\left(35 \times 10^{4}-18 \times 10^{5}\right)$ per gram of faeces. All infected kids continued to shed oocysts in the faeces during the experiment after the prepatent period. The oocysts output did not stop until the end of the experiment. No oocysts were observed in the faeces of kids in group $\mathrm{C}$ over the period of the experiment.

\section{Biochemical and hematological analyses}

The mean \pm SD of the hematological values from different samples of each kid in groups A and B at weekly intervals are presented in Tables 1 and 2, respectively.

The mean hemoglobin $(\mathrm{Hb})$ value was $8.07 \mathrm{~g} / \mathrm{dl}$ before inoculation, and prominent increases were detected at 7 and 42 DPI in groups A and B, respectively, but these differences were not statistically significant. Significant differences were recorded between groups $\mathrm{A}$ and $\mathrm{B}$ $(P=0.037)$ at $21 \mathrm{DPI}$.

Packed cell volume (PCV) value was $25.66 \%$ before inoculation, and the maximum mean PCV (32.9 and $30.1 \%$ ) was observed at 28 and 21 DPI in groups A and B, respectively. The highest values were recorded in group A throughout the experiment, but they were not significantly different compared to group B.

A decrease in the number of WBCs is observed in the peripheral blood of infected kids in group B at 14 DPI; followed by a slow increase from 21 DPI onwards. Clear leukocytosis was recorded at 28 DPI with more than $34 \times 10^{9} / 1$ WBCs in group B. The changes in the number of WBC were not prominent in group A during the experiment and the highest average was $26.6 \times 10^{9} / 1 \mathrm{WBC}$ at 35 DPI. In differential WBC counts, the proportion of granulocytes was elevated in both groups from 28 DPI.

The mean $\pm \mathrm{SD}$ of serum biochemical values from different samples of each kid in groups A and B at weakly intervals are presented in Tables 3 and 4, respectively.

Mean pre-inoculation concentration of $\mathrm{Na}^{+}$was $148.17 \mathrm{mmol} / \mathrm{l}$, and no statistically significant differences were revealed between either groups. The lowest mean concentration detected (127 and $128 \mathrm{mmol} / \mathrm{l})$ was reached at 28 and 21 DPI in groups A and B, respectively.

In group $\mathrm{A}, \mathrm{K}^{+}$concentration declined significantly at 21 DPI and increased afterwards to the end of the experiment. In group $\mathrm{B}, \mathrm{K}^{+}$decreased distinctly on 7 DPI and remained low thereafter.

Mean $\mathrm{Cl}^{-}$concentration prior to inoculation was $95.17 \mathrm{mmol} / \mathrm{l}$, and statistically significant differences were observed between both groups at 21 DPI $(P=.009)$. The lowest mean concentration detected $(64 \mathrm{mmol} / \mathrm{l})$ was recorded at 21 DPI in group A.
The mean albumin concentration was $4.8 \mathrm{~g} / \mathrm{dl}$ before inoculation, and the pattern of changes was different in groups A and B. Albumin concentration decreased from 7 DPI and remained low until 14 and 21 DPI in groups A and $\mathrm{B}$ respectively. The highest levels were observed in group A $(4.7 \mathrm{~g} / \mathrm{dl})$ and $\mathrm{B}(4.9 \mathrm{~g} / \mathrm{dl})$ at 21 and 28 DPI respectively.

Total protein concentration declined slowly from day 7 after inoculation and the lowest mean values were seen at 21 DPI in both groups. The highest mean concentration detected ( 7.3 and $7 \mathrm{~g} / \mathrm{dl}$ ) was reached at $28 \mathrm{DPI}$ in groups A and B respectively, but these values decreased afterwards.

Serum ALT and GGT decreased during the experiment in both groups; however, the ALT levels showed a sharp increase at 21 DPI in group A and decreased thereafter. In both groups, AST activity decreased slowly from 7 DPI, but exhibited no statically significant differences during the experiment.

ALP levels tended to fall in groups A and B during the experiment and a significant decrease in ALP activity was recorded in group A at 35 DPI and B at 7 DPI compared with the activity before inoculation. Significant differences were observed between groups $\mathrm{A}$ and $\mathrm{B}(P<0.02)$ at $7-35$ DPI. Group B showed the lowest levels throughout the observation period.

\section{Discussion}

Coccidiosis is one of the most important diseases of goats kept in large numbers under intensive management conditions (Chhabra and Pandey 1991). Caprine coccidiosis results from complex interactions between parasites and the host, with many factors influencing the severity of the disease. (Jubb et al. 2007). Age, stress, genetic susceptibility, physical condition and the degree of immunity are important in pathogenesis. In coccidiosis, the degree of tissue damage is dependent on the Eimeria species and infective dose of oocysts (Dougschies and Najdrowski 2005; Jolley and Bardsley 2006; Jubb et al. 2007). Among the 16 species of Eimeria from goats (Soe and Pomroy 1992), E. arloingi (Sayin et al. 1980), E. ninakohlyakimovae (Dai et al. 2006) and E. caprina (Norton 1986) are regarded as the most pathogenic species in the world and cause clinical coccidiosis in goats. E. arloingi, E. ninakohlyakimovae, E. alijevi, and E. hirci are the predominant species in many countries (Borgsteede and Dercksen 1996; Harper and Penzhorn 1999; Al-Amery and Hasso 2002; Gul 2007).

Hashemnia et al. (2011) showed some evidence of the life cycle and morphopathological lesions of E. arloingi in Iranian crossbred kids, but the hematological and biochemical changes in infected animals are still not fully understood. The present investigation was conducted to 

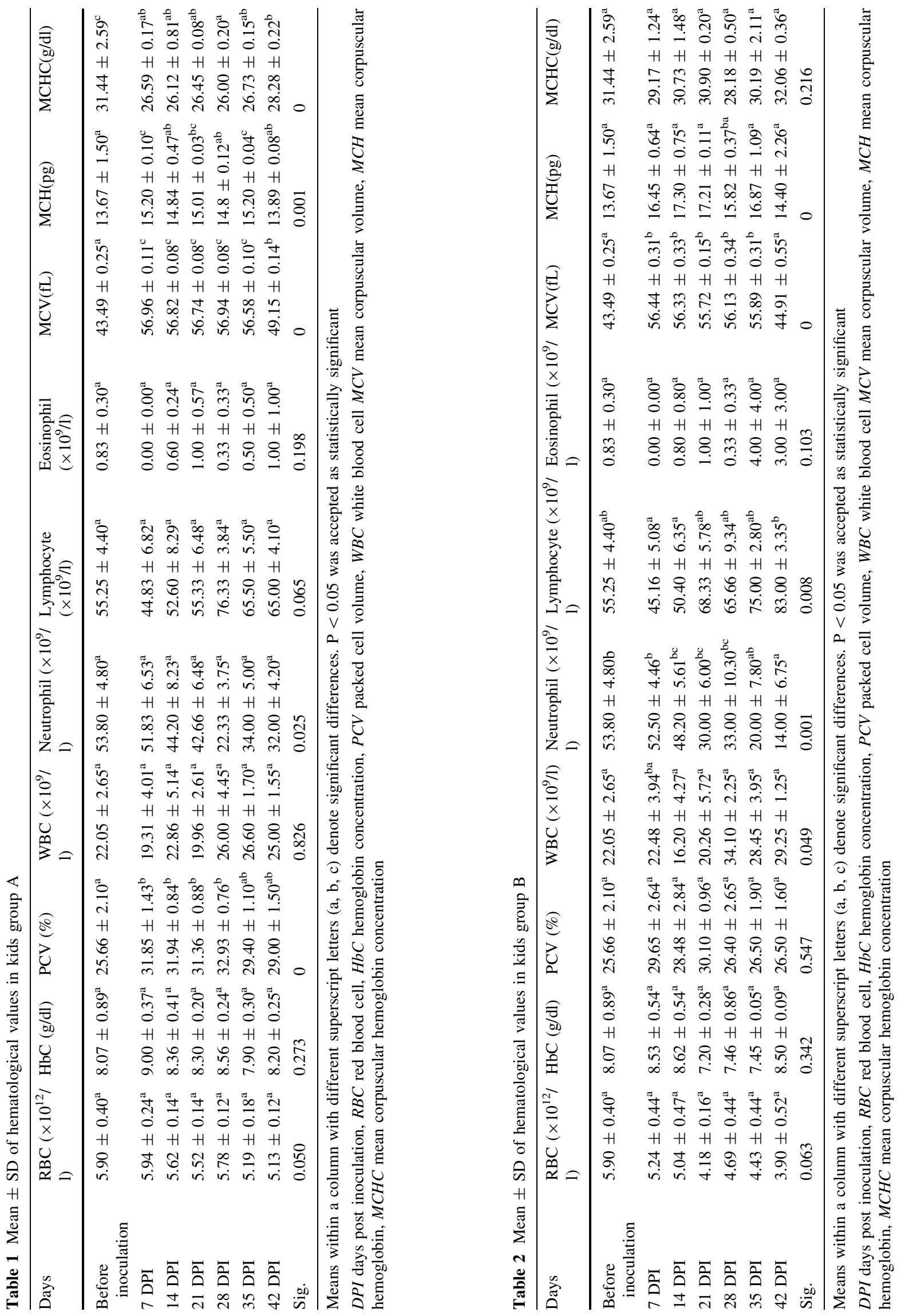


enhance the knowledge of the pathogenic effects of $E$. arloingi infection and to allow a better understanding of the resulting disease. In general, hematological and serum levels of most investigated parameters differed more or less distinctly from those before inoculation, probably due to differences in the inoculating dose and DPI. Therefore, hematological and serum biochemical values of the uninfected animals before inoculation served as reference values in the present experiment.

The results showed that diarrhea, a rise in $\mathrm{PCV}, \mathrm{Hb}$ and WBCs and a fall in ALP, $\mathrm{Na}^{+}, \mathrm{Cl}^{-}$and $\mathrm{K}^{+}$in infected kids. Their degrees of severity varied with the inoculating doses and DPI and tended to increase as the inoculating dose increased. On the other hand, AST, ALT, GGT, albumin and TP showed no pattern and no significant differences compared with the control; however, some differences were observed between groups A and B during the experiment.

The kids began oocyst shedding 16-18 days after inoculation and continued during the experiment. The prepatent period in this study was similar to that reported by Sayin et al. (1980). The lower oocysts output produced from 37 DPI in both groups appeared to indicate that a certain degree of immunity had been developed after infection and/or during the growth of kids. The mean PCV and $\mathrm{Hb}$ value increased in some weeks after inoculation, but measurements in both groups were not significantly different compared to the control. Shumard (1957) found a fluctuation of both PCV and $\mathrm{Hb}$, but levels remained above those indicative of anemia. Chapman (1974) and Dai et al. (2006) stated that mean PCV and Hb significantly increased in ovine coccidiosis. These results are indicative of a decrease in the circulating blood volume resulting from mild to severe diarrhea.

The mean RBC count did not change during the experiment and was between the physiological limits, but the number of WBCs was variable in both groups in different weeks. The number of WBCs decreased at 21 and 14 DPI in groups A and B respectively, and a leucocytosis occurred at 28 DPI in both groups. The increase in the number of WBCs occurs because of increased lymphopoiesis associated with the immune response to the inflammatory agent. It seems that the number of WBS was associated with the inoculating dose and group B showed the highest averages throughout the study. In mammalian and avian coccidiosis, inflammation in the intestine is a common incident and is accompanied by structural and physiological changes which are inimical to parasite development (Wakelin and Rose 1990).

In this experiment, a slight reduction of serum osmolarity and a decline of serum $\mathrm{Na}^{+}, \mathrm{Cl}^{-}$and $\mathrm{K}^{+}$level occurred in infected kids with the development of the coccidia. This was most prominent from 21 to 28 DPI with the onset of diarrhea in both groups and the kids recovered from the depression of electrolyte levels after most parasites had been excreted.

Analysis of total protein concentrations and protein fractions are important in various disease states (Kaneko 1997). In the present study, total protein concentration declined slowly from day 7 after the inoculation and lowest mean values were seen at 21 DPI in both groups. The highest mean concentration detected was reached at 28 DPI in both groups. Albumin concentration decreased from 7 DPI and remained low until 14 and 21 DPI in groups A and $B$ respectively and increased in both groups thereafter. Albumin is considered as a negative acute-phase protein and its concentration tends to decrease mostly during chronic inflammation. Generally, diarrhea is assumed to cause intestinal protein loss and consequently a reduced total protein serum concentration. Increase of serum total protein concentrations result from prominent elevations of the globulin concentration and from a relative decrease of albumin (Latimer et al. 2003; Stockham and Scott 2008). The increase in serum antibody levels was not determined during this study but was previously reported to occur in calf coccidiosis (Holst and Svensson 1994; Faber et al. 2002). This may have contributed to elevated total protein levels, however, only to a low extent.

Turk and Casteel (1997) reported that the serum levels of ALT and AST are increased in acute hepatic degenerations. Increased ALT activity occurs with sublethal hepatocellular injury or necrosis in dog and cat, and liver ALT activity is very low in horses, ruminants and birds.

Although, AST is not liver-specific and is found in most tissue, increased serum AST activity is usually associated with liver or muscle injury. ALP activity has wide reference intervals in ruminants and horse. Therefore, it is not a sensitive indicator of biliary disease (Latimer et al. 2003).

Dash et al. (1991) found that a mixed infection of E. ninakohlyakimovae, E. ahasta and E. arloingi decreased ALP activity in infected kids as compared to uninfected kids. ALT decreased in the infected kids, but the difference was not significant. These species had no effect on serum AST activity. Similar results were found in another study carried out by Dai et al. (2006).

Dai et al. (1991) found various degrees of histopathological lesions in liver of goats infected with E. ninakohlyakimovae naturally and experimentally. They observed various numbers of oocysts in bile and a few endogenous stages of E. ninakohlyakimovae in livers of infected goats.

One of our initial objectives in this experiment was to investigate the damage of $E$. arloingi infection to livers based on histopathological findings and changes in the activities of serum AST and ALT, but the results indicated both enzymes did not significantly fluctuate during the experiment. 
In our study, ALP levels tended to fall in both groups during the experiment and a significant decrease in ALP activity was recorded in group A at 35 DPI and B at 7 DPI compared with the control. The lower ALP was apparently a reflection of the loss of absorptive intestinal epithelium and cachexia resulting from severe diarrhea (Dai et al. 2006).

In previous study we demonstrated that there were various numbers of developmental stages of the parasites, mature large schizonts in the lacteals, and variable inflammatory reaction in the distal jejunum of kids infected with E. arloingi experimentally. However the mesenteric lymph nodes showed marked lymphoid hyperplasia in the cortex associated with a few large schizonts in the lymphatic vessels, the lesions were not found in the abomasums, distal colon, rectum, liver, spleen and pancreas (Hashemnia et al. 2011).

Generally, the Eimeria species which infect the lower small intestine and proximal part of the large intestine of ruminants tend to be more pathogenic than those infecting only the proximal small intestine (Gregory et al. 1980). On the basis of the present experiment, it seems E. arloingi is one of the most common pathogenic species in kids.

\section{Conclusion}

This study confirms that $E$. arloing $i$ is a highly pathogenic species in kids, and also caprine coccidiosis has significant effects on PCV, $\mathrm{Hb}$, WBCs, ALP, $\mathrm{Na}^{+}, \mathrm{Cl}^{-}$and $\mathrm{K}^{+}$. Therefore, biochemical and hematological parameters can be a suitable indicator in caprine coccidiosis.

\section{References}

Abo-Shehada MN, Abo-Farieha HA (2003) Prevalence of Eimeria species among goats in northern Jordan. Small Rum Res 49:109-113

Al-Amery MAY, Hasso SA (2002) Laboratory diagnosis of novel species of Theileria hirci, Eimeria caprovina and Eimeria pallida in goats in Iraq. Small Rum Res 44:163-166

Balicka-Ramisz A (1999) Studies on coccidiosis in goats in Poland. Vet Parasitol 81:347-349

Borgsteede FHM, Dercksen D (1996) Coccidial and helminth infections in goats kept indoors in the Netherlands. Vet Parasitol 61:321-326

Burtis CA, Ashwood ER (1994) Textbook of clinical chemistry, 2nd edn. Saunders, Philadelphia

Bush AO, Fernandez JC, Esch GW, Seed JR (2001) Parasitism: The diversity and ecology of animal parasites. Chapter 3 , the Protozoa. Cambridge University Press, Cambridge, pp 42-102

Chapman HD (1974) The effects of natural and artificially acquired infections of coccidian in lambs. Res Vet Sci 16:1-6

Chhabra RC, Pandey VS (1991) Coccidia of goats in Zimbabwe. Vet Parasitol 39:199-205
Cox FEG (1998) Control of coccidiosis: lessons from other sporozoa. Int J Parasitol 28:165-179

Dai YB, Lin MC, Zhang SX, Fu AQ (1991) Hepatic coccidiosis in the goat. Int J Parasitol 21:381-382

Dai YB, Liu XY, Liu M, Tao JP (2006) Pathogenic effects of the coccidium Eimeria ninakohlyakimovae in goats. Vet Res Commun 30:149-160

Dash B, Misra SC, Panda MR (1991) A note on serum enzyme activity in experimental coccidiosis in kids. Indian Vet $\mathbf{J}$ 12:185-186

Dougschies A, Najdrowski M (2005) Eimeriosis in cattle: current understanding. J Vet Med 52:417-427

Faber JE, Kollmann D, Heise A, Bauer C, Failing K, Burger HJ, Zahner H (2002) Eimeria infections in cows in the periparturient phase and their calves: oocyst excretion and levels of specific serum and colostrum antibodies. Vet Parasitol 104:1-17

Faizal ACM, Rajapakse RPVJ (2001) Prevalence of coccidia and gastrointestinal nematode infections in crossbred goats in the dry areas of Sri Lanka. Small Rum Res 40:233-238

Gregory MW, Joyner LP, Catchpole J, Norton CC (1980) Ovine coccidiosis in England and Wales 1978-1979. Vet Rec 106:461-462

Gul A (2007) The Prevalence of Eimeria species in goats in Igdir. Turk J Vet Anim Sci 31:411-414

Harper CK, Penzhorn BL (1999) Occurrence and diversity of coccidia in indigenous, Saanen and crossbred goats in South Africa. Vet Parasitol 82:1-9

Hashemnia M, Khodakaram-Tafti A, Razavi SM, Nazifi S (2011) Experimental caprine coccidiosis caused by Eimeria arloingi: Morphopathologic and electron microscopic studies. Vet Res Commun DOI 10.1007/s11259-011-9511-9

Holst H, Svensson C (1994) Changes in the blood composition of calves during experimental and natural infections with Eimeria alabamensis. Res Vet Sci 57:377-383

Jain NC (1986) Schalm, s Veterinary hematology, 4th edn. Lea and Febiger, Philadelphia, pp 20-80

Jalila A, Dorny P, Sani R, Salim NB, Vercruysse J (1998) Coccidiosis infections of goats in Selangor, peninsular Malaysia. Vet Parasitol 74:165-172

Jolley WR, Bardsley KD (2006) Ruminant coccidiosis. Vet Clin Food Anim 22:613-621

Jubb KVF, Kennedy PC, Palmer N (2007) Pathology of domestic animals, Vol. 2, 5th edn. Academic Press Inc, London, pp 264-267

Kaneko JJ (1997) Serum proteins and dysproteinaemias. In: Kaneko JJ, Harvey JW, Bruss ML (eds) Clinical biochemistry of domestic animals, 5th edn. Academic, San Diego, pp 117-138

Khodakaram-Tafti A, Mansourian M (2008) Pathologic lesions of naturally occurring coccidiosis in sheep and goats. Comp Clin Pathol 17:87-91

Koudela B, Bokova A (1998) Coccidiosis in goats in the Czech Republic. Vet Parasitol 76:261-267

Latimer KS, Mahaffey EA, Prasse KW (2003) Veterinary laboratory medicine: Clinical Pathology, 4th edn. Iowa State Press, Iowa

Levine ND, Ivens V (1970) The coccidian parasite (protozoa, sporozoa) of ruminants. Illinois Biological Monograph 44. University of Illinois Press, Urbana, p 278

MAFF (1977) Manual of veterinary parasitological laboratory techniques. HMSO, London

Norton CC (1986) Coccidia of domestic goats, Capra hircus, with notes on Eimeria ovinoidalis and E. bakuenis (E. ovina) from sheep Ovis aries. Parasitol 92:279-289

Radostits OM, Blood DC, Gay CC (1994) Veterinary medicine, 6th edn. Bailliere Tindall, London, pp 879-886

Razavi SM, Hassanvand A (2007) A survey on prevalence of different Eimeria species in goats in Shiraz suburbs. J Fac Vet Med Univ Tehran 61:373-376 
Sayin F, Dincer S, Milli U (1980) The life cycle and pathogenicity of Eimeria arloingi (Marotel, 1905) Martin, 1909, in Angora kids and an attempt at its transmission to lambs. Zentrabl Vet Med B 27:382-397

Shumard RF (1957) Studies on ovine coccidiosis. Some physiological changes taking place in experimental infections with Eimeria ninakohlyakimovae (Yakimove and Rastegaeva, 1930) and Eimeria faurei (Moussu and Martole, 1901). J Parasitol 43:548-554

Soe AK, Pomroy WE (1992) New species of Eimeria (Apicomplexa: Eimeriidae) from the domesticated goat Capra hircus in New Zealand. Syst Parasitol 23:195-202
Soulsby EJL (1982) Helminths, arthropods and protozoa of domesticated animals $7^{\text {th }}$ ed. Bailliere Tindall and Company, London, pp 599-606

Stockham SL, Scott MA (2008) Fundamentals of veterinary clinical pathology, 2nd edn. Iowa, USA

Turk JR, Casteel SW (1997) Clinical biochemistry in toxicology. In: Kaneko JJ, Harvey JW, Bruss ML (eds) Clinical biochemistry of domestic animals. Academic Press, California, pp 829-835

Wakelin D, Rose ME (1990) Immunity to coccidiosis. In: Long PL (ed) Coccidiosis of man and domestic animals. CRC Press, Boca Raton, FL, pp 281-306 